\title{
MINIREVIEW
}

\section{How viruses infiltrate the central nervous system}

\author{
A. MICHALICOVÁ ${ }^{1}, \mathrm{~K} . \mathrm{BHIDE}^{3}, \mathrm{M}$. BHIDE ${ }^{1,3}, \mathrm{~A} . \mathrm{KOVÁC}^{1,2^{2}}$
}

\begin{abstract}
${ }^{1}$ Institute of Neuroimmunology Slovak Academy of Sciences, Dúbravská cesta 9, 845 10, Bratislava, Slovak Republic; ${ }^{2}$ Department of Pharmacology and Toxicology, The University of Veterinary Medicine and Pharmacy, Komenského 73, 041 81, Košice, Slovak Republic; ${ }^{3}$ Laboratory of Biomedical Microbiology and Immunology, The University of Veterinary Medicine and Pharmacy, Košice, Slovak Republic
\end{abstract}

Received December 1, 2016; revised January 23, 2017; accepted September 26, 2017

\begin{abstract}
Summary. - Central nervous system is protected by the blood-brain barrier, which represents a physical, metabolic and transport barrier and is considered to be a part of a highly dynamic system termed neurovascular unit. Several pathogens, among them viruses, are able to invade the brain. Traversal of viruses across the blood-brain barrier is an essential step for the invasion of the central nervous system and can occur by different mechanisms - by paracellular, transcellular and/or by "Trojan horse" pathway. Penetration of viruses to brain can lead to the blood-brain barrier dysfunction, including increased permeability, pleocytosis and encephalopathy. Viruses causing the central nervous system infections include human immunodeficiency virus type 1, rhabdovirus, different flaviviruses, mouse adenovirus type 1, herpes simplex virus, influenza virus, parainfluenza virus, reovirus, lymphocytic choriomeningitis virus, arbovirus, cytomegalovirus, mumps virus, parvovirus B19, measles virus, human T-cell leukemia virus, enterovirus, morbillivirus, bunyaviruses, togaviruses and others. In this review we summarized what is known about the routes of how some viruses enter the brain and how neurons and glial cells react to infection.
\end{abstract}

Keywords: blood-brain barrier; CNS infection; virus

\section{Contents:}

1. Blood-brain barrier and its role in pathogen infections

2. Human immunodeficiency virus 1

3. Rabies virus

4. Flaviviruses (West Nile virus, tick-borne encephalitis virus, Japanese encephalitis virus)

4.1 West Nile virus (WNV)

4.2 Tick-borne encephalitis virus (TBEV)

"Corresponding author. E-mail: andrej.kovac@savba.sk; phone: +421-2-54788100-410.

Abbreviations: $\mathrm{CNS}=$ central nervous system; $\mathrm{BBB}=$ blood-brain barrier; TJs = tight junctions; HIV = human immunodeficiency virus; $\mathrm{AIDS}=$ acquired immune deficiency syndrome; $\mathrm{RV}=$ rabies virus; $\mathrm{WNV}=$ West Nile virus; JEV = Japanese encephalitis virus; $\mathrm{TBEV}=$ tick-borne encephalitis virus; MAV-1 = mouse adenovirus type 1
4.3 Japanese encephalitis virus (JEV)

5. Mouse adenovirus type 1

\section{Blood-brain barrier and its role in pathogen infections}

Infections of central nervous system (CNS) are important cause of morbidity and mortality all over the world (Kim, 2008). Although, CNS is protected by physiological barriers separating the bloodstream and the brain, several pathogens are able to invade the brain (Nassif et al., 2002). The bloodbrain barrier (BBB) is a physical, metabolic and transport barrier and it is considered to be a part of a highly dynamic system called neurovascular unit (Kousik et al., 2012; Spindler and Hsu, 2012; Wong et al., 2013). The BBB is formed by brain endothelial cells that line cerebral microvessels 
(Abbott et al., 2006). Adjacent endothelial cells are strongly attached to each other by various types of adhesive structures or cell-to-cell junctions, called tight junctions (TJs), which ensure the integrity of the BBB (Michiels, 2003). The proper functioning of the brain depends on functional interactions of endothelial cells with the other cells of the CNS, including neurons, pericytes, mast cells and glia.

Traversal of pathogen across the BBB is an essential step for the invasion of the CNS (Bencurova et al., 2011). Penetration of pathogens to the brain can lead to the BBB dysfunction, including increased permeability, pleocytosis and encephalopathy. Pathogens can cross the BBB by paracellular, transcellular, and/or by "Trojan horse" mechanism (Kim, 2008). Transcellular pathway refers to the penetration of pathogen through the barrier cells without any evidence of microorganisms between the cells or of intracellular damage of TJs. Paracellular pathway is characterized by the microbial penetration between barrier cells with or without TJs damage, while the "Trojan horse" mechanism involves microbial penetration in infected phagocytes. However, most pathogens penetrating the BBB paracellularly or by the "Trojan horse" mechanism are able to cross it also transcellularly (Kim, 2008; Pulzova et al., 2009). Mechanisms of the BBB disruption mediated by paracellular entry of viruses involve alterations in expression or phosphorylation of TJs proteins, disruption of the basal lamina, and disruption of the actin cytoskeleton. The direct implication of viral gene products in $\mathrm{BBB}$ disruption is very rare (e.g. human immunodeficiency virus 1 ).

Among notorious viral agents that cause CNS infections are human immunodeficiency virus type 1, rhabdovirus (rabies), different flaviviruses (West Nile virus, Japanese encephalitis virus, tick-borne encephalitis virus, St. Luis encephalitis virus or Murray Valley encephalitis virus), mouse adenovirus type 1 , herpes simplex virus, influenza virus, parainfluenza virus, reovirus, lymphocytic choriomeningitis virus, arbovirus, cytomegalovirus, mumps virus, parvovirus B19, measles virus, human T-cell leukemia virus, enterovirus, morbillivirus (Nipah and Hendra virus), bunyaviruses, togaviruses and others (Pulzova et al., 2009; Spindler and Hsu, 2012).

Transcellular and paracellular permeability of the BBB can be modulated by various factors, such as vasogenic factors, growth factors, cytokines and chemokines, matrix metalloproteinases, free radicals, and lipid mediators. The mechanisms employed by infectious agents to compromise the $\mathrm{BBB}$ depend on these factors, and thus the mode of $\mathrm{BBB}$ crossing and severity of damage varies a lot. In some cases, the BBB damage can be caused by microbial products only, while in the majority of cases, multiple factors are responsible for the disruption (Spindler and Hsu, 2012). Among this multifactorial interplay, protein-protein interactions between pathogen ligands and host receptors are crucial to trigger the translocation processes, especially through the paracellular and transcellular ways (Bencurova et al., 2011).

\section{Human immunodeficiency virus 1}

The human immunodeficiency virus (HIV) is a lentivirus belonging to the family of retroviruses (Vigorito et al., 2015). HIV-1 infection affects around 39 million individuals worldwide, of these more than 3 million are children under the age of 15 (Sheets et al., 2016). The clinical signs of acute HIV infection are similar to those in non-HIV infected patients: headache, fever, night sweating, purulent nasal discharge, nasal block, and posterior dripping (Piot and Colebunders, 1987; Sanjar et al., 2011). In later stages, HIV symptoms include weight loss, malaise, fatigue and lethargy, anorexia, abdominal discomfort, diarrhoea, itching, amenorrhea, lymphadenopathy and splenomegaly. Acquired immune deficiency syndrome (AIDS) represents the most severe stage of HIV infection and is characterized by the presence of neurologic abnormalities, opportunistic infections and tumors resulting from a profound cellular immunodeficiency (Piot and Colebunders, 1987).

As far as the molecular processes involved in encephalitis and BBB disruption are concerned, HIV-1 is one of the best-studied viruses (Spindler and Hsu, 2012). HIV replicates by infecting and destroying primarily CD4+ T cells, which are essential for the normal function of the human immune system. The decline of CD4+ T cells causes a progressive immune suppression, resulting in extreme vulnerability to disease and opportunistic infections, like pneumocystis pneumonia and toxoplasmic encephalitis. The terminal stage of HIV viral progression, AIDS, is characterized by the fall of CD4+ cell count below $200 / \mathrm{mm}^{3}$, and complications with secondary infections (Vigorito et al., 2015). HIV-1 invades the CNS by a "Trojan horse" mechanism, via infected blood cells that cross the BBB either paracellularly or transcellularly (Mishra and Singh, 2014; Spindler and Hsu, 2012). Infected monocytes pass through the BBB during normal turnover of perivascular macrophages or as a result of the production of proinflammatory mediators, like CCL2, which compromise the $\mathrm{BBB}$. Another sources of the BBB infection can be by the penetration of infected CD4+ T cells, direct entrance of the virus or entrance of the virus by transcytosis of brain microvascular endothelium (Ghafouri et al., 2006). After the virus invasion, microglia might become infected and contribute to the production of virus. The HIV-envelope glycoproteins, expressed on the surface of infected cells mediate cell-to-cell fusion with cells that express both CD4+ and HIV co-receptor, resulting in the formation of large multinucleotid giant cells, which also produce virus before they eventually die (Gonzalez-Scarano and Martin-Garcia, 2005) (Fig. 1). The disruption of the BBB is followed by a series of processes caused by the neurotoxic activity of different HIV-1 proteins, such as Tat, gp120, Nef, Vpr and others (Maubert et al., 2015). 


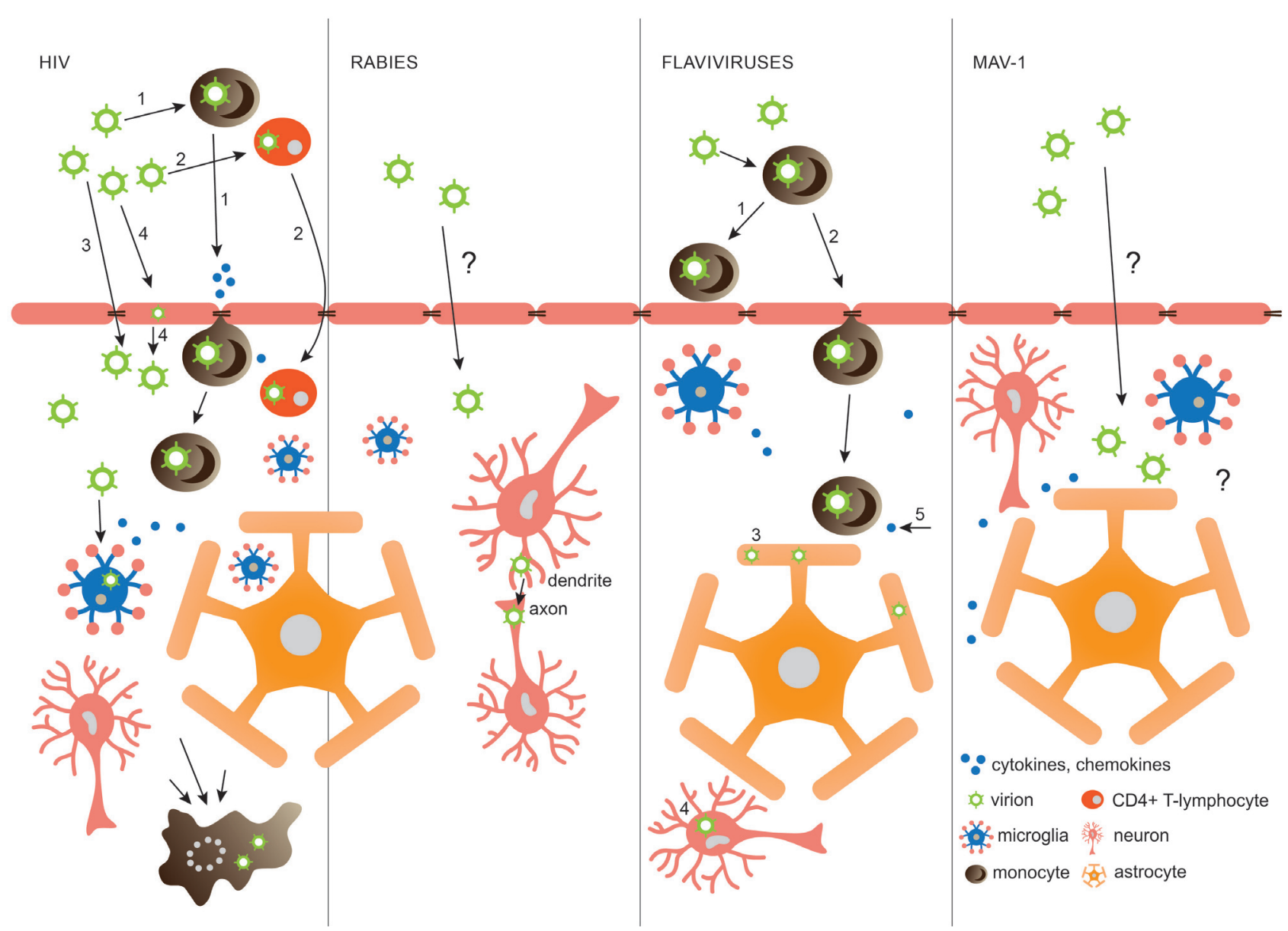

Fig. 1

Routes of viral entry into CNS

HIV-1 utilises a „Trojan horse" mechanism of entry by travelling in infected monocytes (1). These monocytes pass through the BBB during normal turnover of perivascular macrophages or as a result of the production of pro-inflammatory mediators, like CCL2, which compromise the BBB. The penetration of infected CD4+ T cells can be another source of HIV infection in the brain (2). Other probable cause of brain infection might be the direct entrance of the virus (3) or entrance of the virus by transcytosis of brain microvascular endothelial cells (4). After the virus penetration across the BBB, microglia might become infected and contribute to the production of virus. The HIV-envelope glycoproteins, expressed at the surface of infected cells mediate cell-to-cell fusion with cells that express both CD4+ and HIV co-receptor, resulting in the formation of large multinucleated giant cells, which also produce virus before they eventually die. Astrocyte infection is known to be restricted. The mechanism of rabies penetration across the BBB is unknown. After the CNS infection, rabies virions are released at the synapse and use retrograde trans-synaptic pathway to infect neighbouring neurons. CNS infection by flaviviruses occurs either through the adherence of the virus to brain microvascular endothelial cells (1) or infiltration of infected monocytes across the BBB (2). Viral infiltration causes the infection of BBB and CNS cells. Infection of astrocytes leads to chemokine production facilitating further recruitment of monocytes and macrophages (3). Infected neurons undergo apoptosis and activate the resident microglia which produces an inflammatory response (4). Production of inflammatory cytokines, chemokines, enzymes and matrix-metalloproteinases (5) leads the degradation of endothelial barrier and the release of inflammatory factors recruiting CD4+ and CD8+ Tlymphocytes into the CNS parenchyma, what can subsequently lead to further inflammation and damage of the CNS. Encephalitis caused by MAV-1 is characterized by recruitment of inflammatory cells, secretion of cytokines and chemokines, alteration of tight junctions protein levels and localization in brain endothelial cells. These processes lead to neuroinflammation, neuronal damage and the BBB disruption. The mechanisms used by MAV-1 to penetrate the BBB remain unclear.

\section{Rabies virus}

The rabies virus (RV) belongs to the genus Lyssavirus of the Rhabdoviridae family (Paweska et al., 2006). It infects practically all warm-blooded organisms and it spreads to the human through infected saliva by animal bites or scratches. RV remains an important worldwide health problem causing more than 70,000 human deaths annually (Wang et al., 2013). It is endemic in most African and Asian countries (Nel, 2013). 
Clinical manifestations of rabies in humans have two forms. The furious form ( $80 \%$ of infections) is characterized by hydrophobia, excitation with spasm of inspiratory muscles, larynx and pharynx precipitated by attempts to drink and episodes of hallucinations. Animals are often extremely aggressive and they randomly attack objects, other animals or humans. The numb form of rabies (20\% of infections) is characterized by weakness and flaccid paralysis, which sometimes causes misdiagnosis at the onset of this clinical form. In both forms, survival after the onset of symptoms is rarely more than 7 days (Schnell et al., 2010).

$\mathrm{RV}$ is mainly transmitted via saliva following a bite from an infected animal, most often by dogs and cats or through mucous membranes, but not through intact skin (Finnegan et al., 2002). Another reservoirs and transmitters of rabies are coyotes, foxes, jackals, mongooses, raccoons, skunks, wolves and bats (Arai, 2005). It has long been suggested that a rabies infection is lethal in humans once the virus reaches the CNS. However, this concept was challenged by an analysis of a small number of rabies patients, revealing that the BBB played a major role in protection against this virus. It has been shown that the main reason for the survival of rabies patients (animals) was enhanced BBB permeability, which allowed immune cells to enter the tissues of the CNS and fight the infection (Roy and Hooper, 2008; Wang et al., 2013).

RV pathogenesis is a multigenic trait (Dietzschold et al., 2005). RV glycoprotein plays a crucial role in the pathogenesis of RV infection by controlling the rate of virus uptake and trans-synaptic virus spread, and by regulating the rate of virus replication (Dietzschold et al., 2008). Moreover, it is suggested that viral elements, regulating gene expression, especially expression of the L gene, are also likely to play a role in RV pathogenesis (Dietzschold et al., 2005).

The RV binds to the nicotinic acetylcholine receptors at the neuromuscular junction and travels within motor and sensory axons to the CNS. There is also the spread of the virus from the CNS along neuronal pathways, particularly involving parasympathetic nervous system responsible for the infection of salivary glands, skin, heart and other organs. $\mathrm{RV}$ is then secreted into the saliva and can be transmitted to other hosts (Jackson, 2000) (Fig. 1).

\section{Flaviviruses (West Nile virus, tick-borne encephalitis virus, Japanese encephalitis virus)}

The genus Flavivirus of the family Flaviviridae consists of more than 70 RNA viruses, involving multiple long known human, animal, and zoonotic pathogens (Ashraf et al., 2015; Blazquez et al., 2014; Huhtamo et al., 2014). They are transmitted by either mosquitoes or ticks and they are the cause of either encephalitis or systemic haemorrhagic septicemia in animals and/or humans (McVey et al., 2013).
Nowadays, flaviviruses are found on all continents except Antarctica (Ashhurst et al., 2013). As a result of different factors, such as globalization of travel and trade, climate warming, or changes in land use and vector behaviour, different flaviviruses are currently becoming global health problem (Blazquez et al., 2014).

Mechanism of passing of flavivirus to the CNS remains incompletely understood, but it is suggested that proteinprotein interactions at the $\mathrm{BBB}$ may be crucial (Turtle et al., 2012). Flaviviruses disrupt the BBB indirectly through the effects of systemic inflammatory cytokines or directly by binding to different structural proteins, like claudins (Neal, 2014). Viral infiltration causes the infection of BBB and CNS cells. Infection of astrocytes leads to chemokine production facilitating further recruitment of monocytes and macrophages. Infected neurons undergo apoptosis and activate the resident microglia, which produce an inflammatory response. Production of inflammatory cytokines (e.g. TNF- $\alpha$, IL1 $\beta$, INF- $\gamma$ and IL-4), chemokines (e.g. CCL2, CCL5, CXCL9, CXCL10), enzymes (COX2) and matrixmetalloproteinases leads the degradation of endothelial barrier and the release of inflammatory factors recruiting CD4+ and CD8+ T lymphocytes into the CNS parenchyma, what can subsequently lead to further inflammation and damage of the CNS (Daep et al., 2014) (Fig. 1).

\subsection{West Nile virus (WNV)}

WNV is a mosquito-borne flavivirus and its transmission cycle occurs between mosquito vectors and reservoir hosts, like aquatic birds. WNV infection in accidental hosts, such as humans or horses, usually results in low level viremia and plays only a little role in this cycle (Suen et al., 2014). Human-to-human transmission is possible only through the transfusion of blood or organ transplantation (Di Sabatino et al., 2014).

WNV is endemic to numerous parts of Africa, Asia and the Middle East and is now the leading cause of arboviral encephalitis in North America (Ashhurst et al., 2013). It is the most widespread member of the Japanese encephalitis virus complex (Di Sabatino et al., 2014). WNV infection in humans is in the most cases asymptomatic, but mild influenza-like symptoms may occur. In the most vulnerable categories including elderly, chronically ill, and immunocompromised persons, WNV infection can lead to severe encephalitis and even death. In horses, the course of disease is usually subclinical, but some animals may show neurological symptoms and develop fatal encephalitis (Di Sabatino et al., 2014).

The mechanism by which the virus invades the brain is still poorly understood (Suen et al., 2014). WNV-associated encephalitis is characterized by the $\mathrm{BBB}$ disruption, increased infiltration of cells of immune system into the CNS, 
activation of microglia, inflammation and possible loss of neurons. It is also suggested, that WNV may enter into the CNS via transcellular pathway without compromising the $\mathrm{BBB}$. WNV does not induce the cytopathic effect, however induces an expression of claudin-1 and upregulation of VCAM-1 and E-selectin (Pulzova et al., 2009).

Pattern recognition receptor detects the viral RNA (pathogen-associated molecular pattern) and evokes innate immune responses against WNV. Daniels et al. demonstrated that WNV pathogen-associated molecular patterns orchestrate endothelial responses to $\mathrm{WNV}$ via competing with innate immune cytokine signals at the BBB, which normally prevent the entry of pathogens. While Th1 cytokines increases the BBB permeability, type I interferon induced by WNV promotes and stabilizes its function. Induction of innate cytokines by pattern recognition pathways directly regulates the permeability of the $\mathrm{BBB}$ and the formation of TJs via balanced activation of the small GTPases Racl and RhoA, which in turn regulated the transendothelial trafficking of the virus. In vivo experiments on mice with attenuated type I interferon signalling or interferon induction (Ifnar(-/-) Irf7(-/-)) showed enhanced BBB permeability and TJs dysregulation after WNV infection (Daniels et al., 2014).

\subsection{Tick-borne encephalitis virus (TBEV)}

TBEV causes severe encephalitis with serious sequel in humans. Unlike other flaviviruses this virus can be transmitted through non-pasteurized milk of infected cows and goats. However, tick remains major vehicle for virus transmission. The Ixodes ticks (I. scapularis, I. ricinus and I. persulcatus), most prevalent in Central and Eastern Europe, are the primary vectors of TBEV.

The mechanisms underlying how TBEV gains access to the CNS are not completely elucidated. There are several hypothetical routes for TBEV traversal across BBB. These include cytokine-mediated BBB breakdown, "Trojan horse" theory, and viral entry into the brain microvascular endothelial cells, transcytosis, and the release of virus into the brain parenchyma (Ruzek et al., 2011).

Tick borne encephalitis is commonly recognized by a neurological disorder; however other symptoms like mild fever and itching can also occur. The probability of developing the chronic or permanent neuropsychiatic sequelae is nearly $20 \%$ of infected patients (Kaiser, 2008). The virus can infect both meninges and brain. Although, the knowledge on TBEV translocation across the BBB is fragmented, recent research using electron tomography of TBEV infecting neurons has revealed many molecular events that may also take place in brain microvascular endothelial cells infection. The electron tomography revealed direct connections between the tubule-like structures of neurons and viral particles in endoplasmatic reticulum. In the same study, viral particles were also found in cellular microtubules and vacuoles (Bily et al., 2015).

Apart from neurons TBEV infects astrocytes, which are located between synapses and endothelial cells (Potokar et al., 2014). Astrocytes have several functions in the brain, including neuronal support and the most importantly maintenance of TJs in normal and pathologic conditions (Tao-Cheng et al., 1987). It has been shown previously that TBEV infection alters the permeability of the BBB (Ruzek et al., 2011), and astrocytes may be implicated in this process, since these cells regulate blood flow in the brain (Potokar et al., 2014).

\subsection{Japanese encephalitis virus (JEV)}

JEV belongs to a complex containing three other viruses - Saint Luis encephalitis virus, Murray Valley encephalitis virus and West Nile virus (Murphy, 1999). It is an etiologic agent causing the Japanese encephalitis. JEV infection is typically inapparent but can cause clinical disease in humans, horses, and swine (McVey et al., 2013).

JEV is endemic throughout Southeastern and Central Asia and results in approximately 30,000-50,000 cases per year (Ashhurst et al., 2013). In humans, the symptoms can range from a mild febrile illness to severe encephalitis, including seizures, a polio-like illness, and different movement disorders. In fatal cases, pathological changes, such as severe degree of vascular congestion, cerebral oedema, neuronal death, astrocyte activation, and microglial proliferation can be observed in various parts of the nervous system.

JEV can be transmitted between animal and human hosts by Culex species of mosquitoes. Despite the importance of Japanese encephalitis, only little is known about the pathogenesis of human JEV infection, involving the mechanism of its spread to the CNS and viral tropism within the brain. Since in vitro studies have shown that peripheral blood mononuclear cells, including monocytes and macrophages, can be infected and invade the CNS via the antipodal transport of virions or through vascular endothelial cells, it is suggested that JEV may have a peripheral replication cycle. Many flaviviruses have been observed to induce neuronal apoptosis in neurons in vitro and in in vivo rodent models. Neuronal apoptosis is considered to be one of the hallmarks of neurodegenerative infections. JEV has also been shown to cause loss of neurons due to the rough endoplasmic reticulum stress pathway. Viral tropism in neural progenitor stem cells and immature neurons has also been observed in experimental models of JEV infection. However, mature neurons become resistant to JEV-induced apoptosis because of the increased neuronal expression of cellular inhibitors of apoptosis, like Bcl-2 and Bcl-x.

Additionally to neurons, astrocytes and microglial cells can also be infected. Recent studies of human and mouse 
models revealed prominent astrocyte activation, particularly in areas of neuronal damage. Ghoshal et al. (2007) reported significant increase of various proinflammatory mediators, such as inducible nitric oxide synthase, cyclooxygenase 2 , interleukin 6 , interleukin $1 \mathrm{~b}$, tumour necrosis factor alpha, and monocyte chemoattractant protein 1 , in microglial cells following JEV infection, which may play an important role in inducing neuronal cell death (Zhang et al., 2014).

\section{Mouse adenovirus type 1}

Mouse adenovirus type 1 (MAV-1) is a non-humaninfecting adenovirus belonging to the Adenoviridae family of viruses (Hartley and Rowe, 1960; Hsu et al., 2012). MAV-1 infection of immunodeficient mice can result in pneumonia, hepatitis, encephalitis, gastroenteritis, and disseminated disease involving multiple organs (Ashley et al., 2009).

Clinical signs of disease caused by MAV-1 infection in new borne and suckling mice include ruffled coat, lethargy, and terminal burrowing into the cage bedding. Adult mice carrying the severe combined immune deficiency mutation and infected with MAV-1 display also hunching, unsteady gait and poor feeding (Kring et al., 1995).

MAV-1 is similar to human adenovirus in genome and structure, and both viruses cause persistent infections. These properties make MAV-1 a good animal model system for studying adenovirus pathogenesis (Gralinski et al., 2009; Weinberg et al., 2007).

MAV-1 causes both acute and persistent infection in mice and it infects cells of the monocyte/macrophage lineage and brain endothelial cells of the BBB (Guida et al., 1995; Kajon et al., 1998). Infection of endothelial cells is thought to lead to encephalitis. In encephalitis, endothelial cells of the small veins of the meninges and brain are the targets for MAV-1 replication (Charles et al., 1998).

Encephalitis caused by MAV-1 is characterized by recruitment of inflammatory cells, secretion of cytokines and chemokines, and alteration of TJs protein levels and localization in brain endothelial cells (Dallasta et al., 1999; Getts et al., 2008; Gralinski et al., 2009; Chaturvedi et al., 1991; Ivey et al., 2009; Spindler and Hsu, 2012; Verma et al., 2009). These processes lead to neuroinflammation, neuronal damage and the BBB disruption (Gralinski et al., 2009; Charles et al., 1998) (Fig. 1).

\section{Conclusions}

The above review sums up known information about how different viruses invade the central nervous system. It shows that viruses can cross the blood-brain barrier in a wide variety of infectious diseases. In future research the mechanisms of penetration of the viruses across the bloodbrain barrier should be explored as a therapeutic strategy against viral infections of CNS.

Acknowledgements. Authors would like to thank to Dr. Henrieta Dudekova for her help with preparation of graphics. This work was supported by competitive academic grants VEGA 2/0159/15, APVV-14-0547 and structural funds 26240220008, 26240220046.

\section{References}

Abbott NJ, Ronnback L, Hansson E (2006): Astrocyte-endothelial interactions at the blood-brain barrier. Nat. Rev. Neurosci. 7, 41-53. https://doi.org/10.1038/nrn1824

Arai YT (2005): Epidemiology of rabies virus and other lyssaviruses. Nihon Rinsho 63, 2167-2172.

Ashhurst TM, Vreden C, Munoz-Erazo L, Niewold P, Watabe K, Terry RL, Deffrasnes C, Getts DR, Cole King NJ (2013): Antiviral macrophage responses in flavivirus encephalitis. Indian J. Med. Res. 138, 632-647.

Ashley SL, Welton AR, Harwood KM, Van Rooijen N, Spindler KR (2009): Mouse adenovirus type 1 infection of macrophages. Virology 390, 307-314. https://doi.org/10.1016/j. virol.2009.05.025

Ashraf U, Ye J, Ruan X, Wan S, Zhu B, Cao S (2015): Usutu virus: an emerging flavivirus in Europe. Viruses 7, 219-238. https://doi.org/10.3390/v7010219

Bencurova E, Mlynarcik P, Bhide M (2011): An insight into the ligand-receptor interactions involved in the translocation of pathogens across blood-brain barrier. FEMS Immunol. Med. Microbiol. 63, 297-318. https://doi. org/10.1111/j.1574-695X.2011.00867.x

Bily T, Palus M, Eyer L, Elsterova J, Vancova M, Ruzek D (2015): Electron Tomography Analysis of Tick-Borne Encephalitis Virus Infection in Human Neurons. Sci. Rep. 5, 10745. https://doi.org/10.1038/srep10745

Blazquez AB, Escribano-Romero E, Merino-Ramos T, Saiz JC, Martin-Acebes MA (2014): Stress responses in flavivirusinfected cells: activation of unfolded protein response and autophagy. Front. Microbiol. 5, 266. https://doi. org/10.3389/fmicb.2014.00266

Daep CA, Munoz-Jordan JL, Eugenin, EA (2014): Flaviviruses, an expanding threat in public health: focus on dengue, West Nile, and Japanese encephalitis virus. J. Neurovirol. 20, 539-560. https://doi.org/10.1007/s13365-014-0285-Z

Dallasta LM, Pisarov LA, Esplen JE, Werley JV, Moses AV, Nelson JA, Achim CL (1999): Blood-brain barrier TJs disruption in human immunodeficiency virus-1 encephalitis. Am. J. Pathol. 155, 1915-1927. https://doi.org/10.1016/ $\underline{\text { S0002-9440(10)65511-3 }}$

Daniels BP, Holman DW, Cruz-Orengo L, Jujjavarapu H, Durrant DM, Klein RS (2014): Viral pathogen-associated molecular patterns regulate blood-brain barrier integrity via competing innate cytokine signals. M. Bio.5, e01476-14. https://doi.org/10.1128/mBio.01476-14 
Di Sabatino D, Bruno R, Sauro F, Danzetta ML, Cito F, Iannetti S, Narcisi V, De Massis F, Calistri P (2014): Epidemiology of West Nile disease in Europe and in the Mediterranean Basin from 2009 to 2013. Biomed. Res. Int. 2014, 907852. https://doi.org/10.1155/2014/907852

Dietzschold B, Li J, Faber M, Schnell M (2008): Concepts in the pathogenesis of rabies. Future Virol. 3, 481-490. https:// doi.org/10.2217/17460794.3.5.481

Dietzschold B, Schnell M, Koprowski H (2005): Pathogenesis of rabies. Curr. Top. Microbiol. Immunol. 292, 45-56. https://doi.org/10.1007/3-540-27485-5 3

Finnegan CJ, Brookes SM, Johnson N, Smith J, Mansfield KL, Keene VL, McElhinney LM, Fooks AR (2002): Rabies in North America and Europe. J. R. Soc. Med. 95, 9-13. https://doi. org/10.1258/jrsm.95.1.9

Getts DR, Terry RL, Getts MT, Muller M, Rana S, Shrestha B, Radford J, Van Rooijen N, Campbell IL, King NJ (2008): Ly6c+ "inflammatory monocytes" are microglial precursors recruited in a pathogenic manner in West Nile virus encephalitis. J. Exp. Med. 205, 2319-2337. https://doi. org/10.1084/jem.20080421

Ghafouri M, Amini S, Khalili K, and Sawaya BE (2006): HIV-1 associated dementia: symptoms and causes. Retrovirology 3, 28. https://doi.org/10.1186/1742-4690-3-28

Ghoshal A, Das S, Ghosh S, Mishra MK, Sharma V, Koli P, Sen E, Basu A (2007): Proinflammatory mediators released by activated microglia induces neuronal death in Japanese encephalitis. Glia 55, 483-496. https://doi.org/10.1002/glia.20474

Gonzalez-Scarano F, Martin-Garcia J (2005): The neuropathogenesis of AIDS. Nat. Rev. Immunol. 5, 69-81. https://doi. org/10.1038/nri1527

Gralinski LE, Ashley SL, Dixon SD, Spindler KR (2009): Mouse adenovirus type 1-induced breakdown of the blood-brain barrier. J. Virol. 83, 9398-9410. https://doi.org/10.1128/ JVI.00954-09

Guida JD, Fejer G, Pirofski LA, Brosnan CF, Horwitz MS (1995): Mouse adenovirus type 1 causes a fatal hemorrhagic encephalomyelitis in adult C57BL/ 6 but not BALB/c mice. J. Virol. 69, 7674-7681.

Hartley JW, Rowe WP (1960): A new mouse virus apparently related to the adenovirus group. Virology. 11, 645-647. https:// doi.org/10.1016/0042-6822(60)90109-4

Hsu TH, Althaus IW, Foreman O, Spindler KR (2012): Contribution of a single host genetic locus to mouse adenovirus type 1 infection and encephalitis. M. Bio. 3. https://doi. org/10.1128/mBio.00131-12

Huhtamo E, Cook S, Moureau G, Uzcategui NY, Sironen T, Kuivanen S, Putkuri N, Kurkela S, Harbach RE, Firth AE, Vapalahti O, Gould EA, de Lamballerie X (2014): Novel flaviviruses from mosquitoes: mosquito-specific evolutionary lineages within the phylogenetic group of mosquito-borne flaviviruses. Virology 464-465, 320-329. https://doi.org/10.1016/j.virol.2014.07.015

Charles PC, Guida JD, Brosnan CF, Horwitz MS (1998): Mouse adenovirus type- 1 replication is restricted to vascular endothelium in the CNS of susceptible strains of mice. Virology 245, 216-228. https://doi.org/10.1006/viro.1998.9180
Chaturvedi UC, Dhawan R, Khanna M, Mathur A (1991): Breakdown of the blood-brain barrier during dengue virus infection of mice. J. Gen. Virol.72, 859-866. https://doi. org/10.1099/0022-1317-72-4-859

Ivey NS, MacLean AG, Lackner AA (2009): Acquired immunodeficiency syndrome and the blood-brain barrier. J. Neurovirol. 15, 111-122. https://doi.org/10.1080/13550280902769764

Jackson AC (2000): Rabies. Can. J. Neurol. Sci. 27, 278-282. https:// doi.org/10.1017/S0317167100000998

Kaiser R (2008): Tick-borne encephalitis. Infect. Dis. Clin. North Am. 22, 561-575.

Kajon AE, Brown CC, Spindler KR (1998): Distribution of mouse adenovirus type 1 in intraperitoneally and intranasally infected adult outbred mice. J. Virol. 72, 1219-1923.

Kim KS (2008): Mechanisms of microbial traversal of the bloodbrain barrier. Nat. Rev.Microbiol.6, 625-634. https://doi. org/10.1038/nrmicro1952

Kousik SM, Napier TC, Carvey PM (2012): The effects of psychostimulant drugs on blood brain barrier function and neuroinflammation. Front. Pharmacol. 3, 121. https:// doi.org/10.3389/fphar.2012.00121

Kring SC, King CS, Spindler KR (1995): Susceptibility and signs associated with mouse adenovirus type 1 infection of adult outbred Swiss mice. J. Virol. 69, 8084-8.

Maubert ME, Pirrone V, Rivera NT, Wigdahl B, Nonnemacher MR (2015): Interaction between Tat and Drugs of Abuse during HIV-1 Infection and Central Nervous System Disease. Front. Microbiol. 6, 1512.

McVey DS, Kennedy M, Chengappa MM (2013): Veterinary microbiology. Wiley-Blackwell, Ames, Iowa.

Michiels C (2003): Endothelial cell functions. J. Cell. Physiol. 196, 430-443. https://doi.org/10.1002/jcp.10333

Mishra R, Singh SK (2014): HIV-1 Tat C phosphorylates VE-cadherin complex and increases human brain microvascular endothelial cell permeability. BMC Neurosci. 15, 80. https://doi.org/10.1186/1471-2202-15-80

Murphy FA (1999): Veterinary virology. Academic Press, San Diego.

Nassif X, Bourdoulous S, Eugene E, Couraud PO (2002): How do extracellular pathogens cross the blood-brain barrier? Trends Microbiol. 10, 227-232. https://doi.org/10.1016/ $\underline{\text { S0966-842X(02)02349-1 }}$

Neal JW (2014): Flaviviruses are neurotropic, but how do they invade the CNS? J. Infect. 69, 203-215. https://doi. org/10.1016/j.jinf.2014.05.010

Nel LH (2013): Discrepancies in data reporting for rabies, Africa. Emerg. Infect. Dis. 19, 529-533. https://doi.org/10.3201/ eid1904.120185

Paweska JT, Blumberg LH, Liebenberg C, Hewlett RH, Grobbelaar AA, Leman PA, Croft JE, Nel LH, Nutt L, Swanepoel R (2006): Fatal human infection with rabies-related Duvenhage virus, South Africa. Emerg. Infect. Dis. 12, 1965-1967. https://doi.org/10.3201/eid1212.060764

Piot P, Colebunders R (1987): Clinical manifestations and the natural history of HIV infection in adults. West J. Med. 147, 709-712.

Potokar M, Korva M, Jorgacevski J, Avsic-Zupanc T, Zorec R (2014): Tick-borne encephalitis virus infects rat astrocytes but 
does not affect their viability. PLoS One 9, e86219. https:// doi.org/10.1371/journal.pone.0086219

Pulzova L, Bhide M, Andrej K (2009): Pathogen translocation across the blood-brain barrier. FEMS Immunol. Med. Microbiol. 57, 203-213. https://doi.org/10.1111/j.1574695X.2009.00594.X

Roy A, Hooper DC (2008): Immune evasion by rabies viruses through the maintenance of blood-brain barrier integrity. J. Neurovirol. 14, 401-411. https://doi. org/10.1080/13550280802235924

Ruzek D, Salat J, Singh SK, Kopecky J (2011): Breakdown of the blood-brain barrier during tick-borne encephalitis in mice is not dependent on CD8+ T-cells. PLoS One 6, e20472. https://doi.org/10.1371/journal.pone.0020472

Sanjar FA, Queiroz BE, Miziara ID (2011): Otolaryngologic manifestations in HIV disease - clinical aspects and treatment. Braz. J. Otorhinolaryngol. 77, 391-400. https://doi. org/10.1590/S1808-86942011000300020

Sheets RL, Zhou T, Knezevic I (2016): Review of efficacy trials of HIV-1/AIDS vaccines and regulatory lessons learned: A review from a regulatory perspective. Biologicals. 44, 73-89. https://doi.org/10.1016/j.biologicals.2015.10.004

Schnell MJ, McGettigan JP, Wirblich C, Papaneri A (2010): The cell biology of rabies virus: using stealth to reach the brain. Nat. Rev. Microbiol. 8, 51-61.

Spindler KR, Hsu TH (2012): Viral disruption of the blood-brain barrier. Trends Microbiol. 20, 282-290. https://doi. org/10.1016/j.tim.2012.03.009

Suen WW, Prow NA, Hall RA, Bielefeldt-Ohmann H (2014): Mechanism of West Nile virus neuroinvasion: a critical appraisal. Viruses 6, 2796-2825. https://doi.org/10.3390/ $\underline{\mathrm{v} 6072796}$
Tao-Cheng JH, Nagy Z, Brightman MW (1987): Tight junctions of brain endothelium in vitro are enhanced by astroglia. J. Neurosci. 7, 3293-3299.

Turtle L, Griffiths MJ, Solomon T (2012): Encephalitis caused by flaviviruses. QJM 105, 219-223. https://doi.org/10.1093/ gjmed/hcs013

Verma S, Lo Y, Chapagain M, Lum S, Kumar M, Gurjav U, Luo H, Nakatsuka A, Nerurkar VR (2009): West Nile virus infection modulates human brain microvascular endothelial cells tight junction proteins and cell adhesion molecules: Transmigration across the in vitro blood-brain barrier. Virology 385, 425-433. https://doi.org/10.1016/j. virol.2008.11.047

Vigorito M, Connaghan KP, Chang SL (2015): The HIV-1 transgenic rat model of neuroHIV. Brain Behav. Immun. 48, 336-349. https://doi.org/10.1016/j.bbi.2015.02.020

Wang L, Cao Y, Tang Q, Liang, G (2013): Role of the blood-brain barrier in rabies virus infection and protection. Protein Cell. 4 901-903. https://doi.org/10.1007/s13238-013-3918-8

Weinberg JB, Jensen DR, Gralinski LE, Lake AR, Stempfle GS, Spindler KR (2007): Contributions of E1A to mouse adenovirus type 1 pathogenesis following intranasal inoculation. Virology 357, 54-67. https://doi.org/10.1016/j. virol.2006.08.013

Wong AD, Ye M, Levy AF, Rothstein JD, Bergles DE, Searson PC (2013): The blood-brain barrier: an engineering perspective. Front. Neuroeng. 6, 7. https://doi.org/10.3389/ fneng.2013.00007

Zhang Y, Wang Z, Chen H, Chen Z, Tian Y (2014): Antioxidants: potential antiviral agents for Japanese encephalitis virus infection. Int. J. Infect. Dis. 24, 30-36. https://doi. org/10.1016/j.ijid.2014.02.011 